Invenção. Inovação. Gênese instrumental.

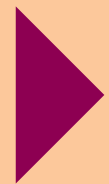




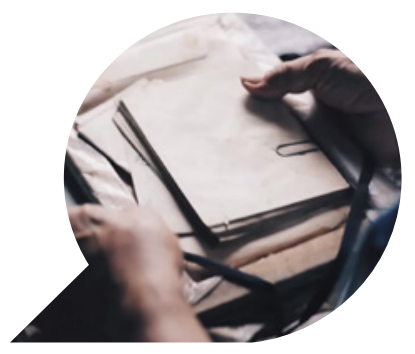

\section{Precisa-se sempre de inventores mas ainda se procuram os inovadores ${ }^{1}$}

On demande toujours des inventeurs et l'on cherche encore les innovateurs

Inventors are the ones always requested but innovators are yet to be found

\section{JEAN-FRANÇOIS CERISIER ${ }^{2}$}

Resumo: Por diversas razões e há décadas, a questão da inovação na educação é brandida como um slogan por numerosos dirigentes políticos, mas também por um número razoável de pedagogos. A mediatização da formação está no centro desta problemática na qual se misturam, demasiadas vezes e sem distinção, as questões com origem na invenção de novas práticas e do papel que nelas desempenham as tecnologias, as que se ligam à socialização destas invenções e aquelas relativas à sua utilidade real. Muito cedo, Geneviève Jacquinot-Delaunay iniciou múltiplos trabalhos que concorrem para elucidar esta problemática. Ela procura mostrar, nomeadamente, como e porquê a especificidade dos media nunca é tomada em conta, mas também procura elaborar propostas visando melhor compreender os processos de inovação e o seu acompanhamento e controle. Este artigo discute as noções de invenção e de inovação na senda dos trabalhos de Geneviève Jacquinot-Delaunay e da comunidade científica para a animação 
da qual ela contribui fortemente numa perspetiva interdisciplinar. Convoca o modelo da instrumentação digital da atividade e as suas duas dimensões subsequentes da mediação e da génese instrumentais para apreender os processos de invenção e de inovação. Propõe, enfim, o modelo de zona proximal de desenvolvimento da instrumentação que confronta sumariamente à realidade da política atual de implantação massiva de tablets táteis no ensino escolar.

Palavras-chave: Invenção; Inovação; Gênese instrumental; Mediação instrumental; Zona proximal de desenvolvimento da instrumentação.

Résumé: Pour diverses raisons, la question de l'innovation dans l'éducation est brandie comme un slogan depuis des décennies par de nombreux dirigeants politiques, mais aussi bon nombre de pédagogues. La médiatisation de la formation est au cour de cette problématique dans laquelle se mêlent trop souvent, sans être distinguées, les questions qui relèvent de l'invention de nouvelles pratiques et du rôle qu'y jouent les technologies, celles qui ont trait à la socialisation de ces inventions et celles relatives à leur utilité réelle. Très tôt, Geneviève Jacquinot-Delaunay a engagé de multiples travaux qui concourent à l'élucidation de cette problématique. Elle cherche notamment à montrer comment et pourquoi la spécificité des médias n'est pratiquement jamais prise en compte, mais aussi à élaborer des propositions visant à mieux comprendre les processus d'innovation et à les piloter. Cet article discute les notions d'invention et d'innovation dans le sillage des travaux de Geneviève Jacquinot-Delaunay et de la communauté scientifique à l'animation de laquelle elle contribue fortement dans une perspective interdisciplinaire. Il convoque le modèle de l'instrumentation numérique de l'activité et ses deux dimensions subséquentes de la médiation et de la genèse instrumentales pour appréhender les processus d'invention et d'innovation. Enfin, il propose le modèle de zone proximale de développement de l'instrumentation qu'il confronte sommairement à la réalité de la politique actuelle de déploiement massif de tablettes tactiles dans l'enseignement scolaire.

Mots-Clés: Invention; Innovation; Médiation instrumentale; Genèse instrumentale; Zone proximale de développement de l'instrumentation. 
Abstract: For various reasons, and for decades, the topic of innovation in education has been flaunted as a slogan by many political leaders but also by many educators. The use of digital media in education is at the heart of this question. Several issues are often intermingled: some related to the invention of new practices and the role played by technology, others related to socialization of these inventions and some others relating to their real value. Geneviève Jacquinot-Delaunay very early undertook numerous researches that contributed to clarify this question. She tries in particular to show how and why the specificity of the media is almost never taken into account. She also undertakes to develop new propositions to understand better the innovation processes and how we can manage them. This article discusses the concepts of invention and innovation in the wake of the work of Geneviève Jacquinot-Delaunay and of the scientific community she greatly contributed to develop and animate in an interdisciplinary perspective. It deals with the model of the digital instrumentation of activity and its two subsequent dimensions - instrumental mediation and instrumental genesis for understanding the invention and innovation processes. Finally, it proposes a new model about the proximal zone of instrumental development and briefly confronts the model with the reality of the current policy of massive deployment of tablet PCs in school education.

Keywords: Invention; Innovation; Instrumental mediation; Instrumental genesis; Proximal zone of instrumental development.

Ouvirás murmurar à tua volta: isso não se pode, e, 
Se se puder, são inovações; Inovações! Seja; mas tantas descobertas nas ciências

e nas artes não o foram?

Guillaume-Thomas Raynal, $1770^{3}$

\section{Precisa-se sempre de inventores}

Muitas investigações foram realizadas e muitas ainda o serão sobre o tema da invenção em geral e da invenção no campo da educação em particular. Esta é uma das razões pelas quais é tão difícil arriscar-se a fazê-las hoje em dia, sobretudo nesta mise en abyme deliberada dos trabalhos de Michel Tardy et de Geneviève Jacquinot-Delaunay, esta última tendo tomado emprestado ao primeiro o título de um capítulo da sua obra O Professor e as imagens (1966) para com ele criar um dos seus artigos mais citados: On demande toujours des inventeurs (1981).

Um e outro reivindicam-se pedagogos ${ }^{4}$. Um e outro dirigem sobre a invenção um olhar de investigador por vezes para interrogar a sua natureza e a dos seus processos genéticos, por vezes para analizar o alcance e o interesse comprovado da realidade dos usos e das situações. Se as suas análises tomam por vezes caminhos diferentes, também muitas vezes convergem, nomeadamente para sublinhar que não devemos confundir invenção, inovação e progresso. Ambos apelam à inovação útil e questionam os meios de aí chegar.

A invenção é um ato de criação, termo cuja etimologia (creatio) o liga diretamente ao ato de engendrar e, portanto, à "ação de estabelecer pela primeira vez" ${ }^{5}$. Distingue-se claramente da inovação que é uma socialização da invenção, ou seja a sua apropriação à escala de uma comunidade. Assim, a inovação pedagógica não designaria apenas os artefatos tecnológicos,

mas também os processos complexos, apoiando-se sobre estes no-

3 Raynal G.-T. (1770), Histoire philosophique et politique des établissements et du commerce des Européens dans les deux Indes (Citação extraída do Littré).

4 Michel Tardy termina a sua obra Le professeur et les images com a afirmação: "Posto isto, pertenço à confraria dos pedagogos". Geneviève Jacquinot-Delaunay, entrevistada em 2007 por Rosa Maria Cardoso Dalla Costa (uma das suas antigas doutorandas), situa a gênese do seu percurso de investigadora na experiência da prática de ensino. "Sempre quis ser professora", começa por responder quando lhe é colocada a questão da origem do seu interesse pelo estudo da relação comunicação-educação.

5 Fonte: Centre national de ressources textuelles et lexicales, http://www.cnrtl.fr/etymologie/ cr\%C3\%A9ation 
vos objetos. Desfocados e dificilmente previsíveis estes processos transformam as conceções e as práticas sociais, os modos de relação entre atores e, ainda mais, a organização, os valores e as finalidades educativas de uma instituição [...] (CHOPLIN et al., 2007).

O progresso, por sua vez, evoca antes a progressão, a ideia de um movimento para frente. Esta noção reenvia a maior parte das vezes para valores positivos, mesmo que tal seja discutido há séculos, e particularmente nos nossos dias, nesta dialética que opõe o culto do progresso ao princípio de precaução. Seja este julgamento de valor sobre o valor genérico da inovação positivo ou não, ele confere ao progresso uma conotação que exige a distinção estrita entre o seu entendimento e o de inovação. Consoante os casos, uma inovação pode assim constituir um progresso ou não em função da avaliação da sua contribuição para o melhoramento de uma situação ou para a resolução de uma dificuldade. Daqui resulta que uma mesma inovação pode ser considerada como um progresso por alguns e como um retrocesso por outros.

Da natureza da transformação de uma invenção em inovação resulta a possibilidade de inovar com "velhas" invenções que ainda não teriam sido socializadas. Pode-se assim fazer novo com o velho, enunciado que contradiz, mas apenas em aparência, o propósito de Geneviève Jacquinot-Delaunay quando afirma que "não é mais possível fazer novo com o velho" (1993). O inverso, ou seja fazer velho com o novo é muito mais frequente. Trata-se mesmo de um comportamento constitutivo de um processo de apropriação, eventualmente evitável, nomeadamente quando um novo equipamento é implantado de uma forma não decidida pelos utilizadores. A capacidade de socializar as invenções (fazer novo com o velho) coloca a questão das políticas de inovação e do papel maior que elas devem conceder à investigação, não como única via para lá chegar mas por princípio. Finalmente,

a escola não pode "continuar a viver como na época da máquina a vapor"6 e ignorar as novas ferramentas para aprender. Por um lado, a modernidade tecnológica não garante nada, sobretudo a inovação pedagógica. [...] (JACQUINOT-DELAUNAY, 2001, p. 392).

6 Geneviève Jacquinot-Delaunay toma emprestada de François Mariet (1989) esta expressão. 
Estas interrogações encontram-se frequentemente nas publicações de Geneviève Jacquinot-Delaunay que fala por experiência própria, visto ser ela autora de várias invenções cuja socialização provocou verdadeiras inovações. Citemos duas maiores. A originalidade da sua abordagem epistemológica, desde logo quando mobiliza a semiologia para mostrar a dificuldade de realizar filmes pedagógicos que não se reduzam ao discurso palrador dos "pedagogos que apenas confiam na palavra - na sua palavra - e desconfiam da imagem"7 (1977, p. 89).

Mesmo que lamentemos que os ensinamentos destes trabalhos quanto à produção de recursos educativos ou à elaboração de políticas públicas tenham sido largamente ignorados, os contributos desta semiótica da didática alimentam e continuarão a alimentar tanto a investigação quanto as práticas profissionais dos concetores mediáticos e dos professores. A segunda inovação diz respeito ao seu posicionamento profissional singular, estabelecido sobre as bases de uma sólida argumentação teórica, traduzindo-se num envolvimento concreto a favor de uma abordagem interdisciplinar das problemáticas de mediatização da formação que associa os contributos e as abordagens das ciências da educação com os das ciências da informação e da comunicação. Ponto de vista epistemológico incômodo e corajoso que ela afirma alto e bom som num artigo breve de título e conteúdo provocadores e de grande impacto: "Sic et Sed sont dans un bateau..." (2004, p. 198). Artigo que se apoia sobre uma análise aprofundada, elaborada alguns anos antes (2001), ao longo da qual expõe as proximidades jovens e gêmeas, as suas interações em torno da problemática partilhada das relações da educação com as tecnologias da informação e da comunicação, o interesse no trabalho nesta interdisciplina, mas também as dificuldades no seu fazer.

Estas duas inovações fornecem um quadro para pensar de forma diferente a invenção, a inovação e a figura do inventor, retratada sem concessões em "On demande toujours des inventeurs", quer se trate do capítulo de Michel Tardy ou do artigo de Geneviève Jacquinot-De-

7 É sob o título "Images et pédagogie", emprestado de Christian Metz (1970) que Geneviève Jacquinot-Delaunay publica os trabalhos resultantes da sua tese de doutoramento intitulada "Structures spécifiques du message audio-visuel didactique" realizada sob orientação de Christian Metz e de Jacques Witwer e defendida em 1975.

8 Nota de tradução: CIC (Ciências da Informação e Comunicação) e CE (Ciências da Educação) estão no mesmo barco. Pode ser encontrada uma versão deste texto em Jacquinot-Delaunay, G. (2006). As Ciências da Educação e as Ciências da Comunicação em Diálogo: a propósito dos media e das tecnologias educativas. In J. Paraskeva e Lia Oliveira (Eds.) Currículo e Tecnologia Educativa. Volume 1. Mangualde: Edições Pedago. Pp. 123-141. 
launay. Elas convidam a fazê-lo mobilizando um paradigma maior nascido da psicologia cognitiva e do qual as ciências da informação e da comunicação se apropriaram, o da instrumentação (RABARDEL, 1995) e seus corolários que são os processos de gênese e de mediação instrumentais.

\section{A abordagem dispositivo arriscando a inovação}

Se a inovação é um questionamento permanente no coração dos atores da educação, a sua constituição em objeto de investigação no seio das ciências da educação é relativamente recente. Michael Fullan (1990, citado por Françoise Cros, 1997, p. 127) situa-a no início dos anos 1960. Num artigo precedente (1996), precisava que as publicações relativas à inovação na educação se preocupavam geralmente menos em caracterizar e teorizar a inovação do que a relatar práticas identificadas como "novas". Esta observação, cuja atualidade provavelmente perdura, reenvia-nos à própria conceção do que é inovação, considerada enquanto processo e produto desse mesmo processo.

O propósito deste artigo não é fazer a história descriminada dos trabalhos conduzidos sobre os processos de inovação no campo da educação. Os principais animadores deste importante debate científico são bem conhecidos e podemos remeter para os seus trabalhos9. Trata-se apenas aqui de referir alguns autores para situar as duas questões próprias da inovação na educação tão frequentemente discutidas por Geneviève Jacquinot-Delaunay e que nos propomos examinar sob o olhar do modelo da instrumentação. Primeiro a questão da gênese da inovação e, depois, a do papel que ela desempenha na mediatização.

Foi seguramente com os trabalhos históricos de Joseph Aloïs Schumpeter, ao longo da primeira metade do século XX, que o conceito de inovação foi objeto de uma teorização que a situou de imediato no campo da economia. Para Schumpeter, são as novidades técnicas mais relevantes, que qualificaríamos hoje de inovações de rutura, muitas vezes consequência de uma descoberta científica, que iniciam novos ciclos econômicos (1974). Atribui um papel determinante à figura do empreendedor no processo de inovação, mesmo que, como mostra

9 Em particular, pode consultar-se o dossier documentário constituído por Olivier Rey e Annie Feyfant (2012) que considera a inovação sob o ângulo das relações que mantem com a criatividade. 
Christian Deblok (2012, p. 4), coloque em causa esta certeza retórica no final da sua vida, questionando a própria natureza da inovação e a do inovador, os processos pelos quais a invenção se converte em inovação e as causas e condições da emergência da novidade num dado lugar e tempo. Para todas estas questões, que permanecem em aberto ainda hoje, Schumpeter não tem resposta, a não ser, como reporta de novo Christian Deblok (2012, p. 5), a evocação de um princípio de indeterminação relativamente à novidade, como testemunham, segundo ele, as descontinuidades manifestas da história das artes.

Geneviève Jacquinot-Delaunay retoma com Hugues Choplin (2002) este princípio de incerteza e de imprevisibilidade constitutivo da inovação para discutir o antagonismo aparente que o opõe à estabilidade dos dispositivos de formação, concebidos em função dos objetivos que lhes são atribuídos. A sua análise apoia-se sobre um estudo de caso, o do projeto Primeiro ciclo científico à medida ${ }^{10}$. Identificam o dispositivo como o lugar onde se partilha o poder de decisão e de ação dos atores humanos com o das tecnologias e do conjunto dos artefactos.

Apoiados em trabalhos realizados nos anos 1990 em torno do conceito de dispositivo (JACQUINOT, MONNOYER, 1999), mostram de que forma as negociações entre os diferentes atores (humanos e não humanos) na conceção e implementação de um dispositivo constituem verdadeiramente a sede da inovação. Se esta proposição não levanta o véu sobre a gênese da inovação (porquê, como), ela situa-lhe o lugar (onde) e o tempo (quando). Para estes autores, o processo de inovação está na abordagem dispositivo (quando) consubstancial do próprio dispositivo (onde).

\section{A mediação instrumental no coração das invenções}

10 "A Université en Ligne (UEL, Universidade Online) é um conjunto coerente de recursos multimédia em ciências, destinado aos estudantes dos primeiros ciclos do ensino superior e a professores. Trata-se de uma realização da rede universitária dos centros de autoformação (RUCA), sustentada pelo ministério do Ensino superior e da investigação para desenvolver novas formas de aprendizagem através das tecnologias de informação e comunicação, e participar numa difusão alargada do saber» (fonte: Website da universidade online, consultado a 24 de novembro de 2014: http://uel.unisciel.fr/). Para uma análise mais aprofundada da UEL ver a obra consagrada a este projeto, sob a direção de Geneviève Jacquinot-Delaunay et d'Elisabeth Fichez (2008); e a tese doutoral defendida por Laurent Petit em 2007, sob orientação de Pierre Mœglin, intitulada "Enjeux scénographiques et industriels de la conception des ressources numériques : le cas de l'université en ligne". 
A atenção dedicada ao papel desempenhado pelos atores não humanos do dispositivo e, mais especificamente, aos artefatos digitais, parece-nos sobretudo reenviar ao conceito de invenção, tentando compreender o que o dispositivo propõe de inédito e em que é que o deve especificamente às tecnologias. A referência subjacente, mas totalmente implícita ao conceito de cognição distribuída (Edwin Huchins, 1995) atribui um papel aos objetos e ao seu sistema de funcionamento na construção da ação. A referência à mediação instrumental e aos trabalhos de Daniel Peraya, ela sim, é explícita. Este último não opõe a mediação humana à mediação tecnológica. Situa uma e outra num continuum em função da parte relativa de uma e de outra (PERAYA, 2010, p. 10) e assume a identificação dos diferentes registos de mediação instrumental pelos quais a instrumentação da atividade humana é transformada, da mesma forma que o sujeito da instrumentação e o seu objeto.

Segundo as propostas de Daniel Peraya, o primeiro destes registos, que qualifica de epistémica (PERAYA, PELTIER, 2012), depois de o ter qualificado durante muito tempo de sémio-pragmática, diz respeito à contribuição da mediação instrumental para a construção do sentido na instrumentação. Encontramos aqui, mas não unicamente, os contributos da semiologia para a compreensão da atividade instrumentada na qual as características do media e da mediatização participam da construção da relação do sujeito com o objeto, ou seja, para nós, da sua relação com a aprendizagem e com o saber.

Um raciocínio próximo interroga não o papel da instrumentação na mediação entre sujeito e objeto mas na relação do sujeito com o seu meio. Esta abordagem inscreve-se numa perspetiva cultural, desde logo considerando que "o verdadeiro lugar da cultura, são as interações individuais!" (SAPIR, 1967). Ele conduz à identificação de diferentes categorias de interações culturais (concetuais, espaciotemporais, relacionais, sociais e poiéticas) suscetíveis de serem transformadas pelo conjunto das características da instrumentação digital (CERISIER, 2011, 2014). As “interações conceituais" que definem as relações do sujeito com a informação e com os saberes são modificadas pela instrumentação digital, especialmente quando ela é mais intensiva. Convém colocar em perspetiva o registo epistêmico da mediação instrumental com a categoria concetual das interações culturais. É precisamente porque a instrumentação digital apresenta ca- 
racterísticas específicas de ordem sémio-pragmática (registo epistémico da mediação instrumental) que ela é suscetível de transformar profundamente as relações individuais e sociais com a informação e com o conhecimento (categoria concetual das interações culturais).

A imagem, por exemplo, inscrita nos diferentes dispositivos destinados a dar-lhe um potencial didático, ou seja, para retomar os termos de Geneviève Jacquinot-Delaunay (2012, p. 128), “própria para instruir", participa desta construção da relação do aprendente com o seu objeto de aprendizagem. Por isso mesmo, recorrer à imagem exige levar em consideração as suas especificidades e o seu papel na mediação instrumental e nas interações culturais. Ter isto em conta é permitir-se realmente a possibilidade da invenção, na verdade a inovação. Contudo, Geneviève Jacquinot-Delaunay observava em 1981 os tropeços que se perpetuam na utilização pedagógica da imagem que "testemunham uma ausência - recusa ou incapacidade - de procura de uma "escrita", ou seja, de uma exploração de um modo de significar específico em função da intenção de instruir"(1981, p. 6). Analisando a televisão como um "terminal cognitivo", convida a não a considerar - o que ela é, claro —, nem como "objeto de conhecimento" (pedagogia da televisão) nem como "suporte de conhecimento" (aprender "com" ou "através" da televisão) mas, a montante, [...] como relação entre pessoas o que passa pela mediação de um objeto numa determinada situação. [...] (JACQUINOT-DELAUNAY, 1995).

Quatro décadas depois dos seus trabalhos sobre o filme pedagógico, sobre o qual dizia que ou "se parece com o cinema de ficção e aceita não ser didático para não ser aborrecido", ou "volta as costas ao cinema de ficção e aceita não ser aborrecido para ter a certeza de que não é aborrecido" (2012), a questão mantém-se no que diz respeito à criação de recursos e serviços digitais educativos. Hoje, o objeto mais emblemático desta dialética é, provavelmente, o serious game. As suas qualidades fazem dele ora um jogo com o qual se joga verdadeiramente sem aprender muito, ora um recurso verdadeiramente educativo de fraco game play. As tecnologias mudam, mas as problemáticas persistem e sabemos bem que, muito pelos trabalhos de Schumpeter, as determinantes econômicos da inovação se sobrepõem muitas vezes às necessidades pedagógicas. Para Geneviève Jacquinot-Delaunay,

um media empurra o outro e cada novo gadget constitui uma oportunidade para recolocar a pseudo-questão fundamental: “O 
media X vai transformar o ensino?" As respostas reduzem-se todas, mais ou menos, a uma defesa e ilustração da máquina em causa: ela é apresentada como útil pelo tecnólogo, e o seu uso como educativo, pelo menos postulado em termos de objetivo da sociedade (JACQUINOT-DELAUNAY, 1981, p. 5).

Contudo, as determinantes da invenção estão claramente identificadas e residem na tomada em consideração, sem concessões, das especificidades dos media. Ninguém duvida que há muitos inventores no domínio da mediatização das atividades de aprendizagem e, mais geralmente, na mediatização da educação. Ninguém duvida, também, ouvindo os mais recentes anúncios políticos, que a esperança suscitada pela elaboração de uma verdadeira estratégia do Estado para fazer entrar a escola na era do digital, saudada pelos investigadores, em 2012, como um primeiro passo tímido mas corajoso, seria de novo desapontada por uma política centrada na implantação maciça de equipamentos que não viria a garantir a retoma econômica tão esperada pelo setor da educação.

Ao dar inteligibilidade às transformações operadas pela instrumentação digital na educação, o conceito de mediação instrumental permite apreender o que são verdadeiramente estas invenções que repousam sobre o uso de novas tecnologias ou então sobre o uso novo de tecnologias mais antigas. No entanto, se a mediação instrumental esclarece a natureza destas invenções (o que elas mudam e de que maneira), ela não fornece qualquer indicação sobre a sua gênese. Sem dúvida, podemos aproximar esta impotência explicativa do fato da invenção ser difícil de apreender de outra forma que não um "movimento", no sentido proposto por Hugues Choplin (2009), quando a mediação instrumental se inscreve numa lógica que articula substância e relação (ibid.). Segundo Hugues Choplin, o

movimento implica considerar que o essencial depende da maneira como os sujeitos são levados por, ou sobrecarregados por, "alguma coisa" maior que eles", enquanto a "substância" "implica considerar que o essencial se passa nos sujeitos» e a "relação" postula o primado do que «se passa entre os sujeitos - entre os aprendentes e os professores, entre estes atores e o dispositivo". [...] (CHOPLIN, 2009, p. 556). 


\section{A inovação (socialização das invenções) à luz da gênese instrumental}

O modelo da instrumentação descreve o processo de construção do instrumento pelo sujeito que associa artefato e esquema de utilização. Coloca-se então a questão dos elementos percursores desta gênese instrumental. Quais são os elementos que a suscitam, que a iniciam e que a tornam possível? No que concerne à problemática da invenção, a questão é a de saber como uma invenção pode ser tida em conta pelo sujeito na instrumentação da sua atividade. Uma explicação possível consiste em considerar a instrumentação como uma aprendizagem e em encará-la na articulação entre a sua dimensão individual e a sua dimensão coletiva.

A teoria da "zona proximal de desenvolvimento", elaborada por Lev Vygotsky (1930) e muitas vezes retomada, prevê que um sujeito pode realizar tarefas que não poderia realizar sozinho, desde que os seus conhecimenos e competências prévias sejam suficientes para realizar estas tarefas na proximidade de sujeitos mais avançados. Por analogia, seria a gênese da instrumentação, para um determinado sujeito, essencialmente subordinada à existência de um ambiente social favorável do qual poderia extrair as práticas instrumentais novas, na condição, porém, destas serem próximas das suas práticas anteriores? A apropriação das práticas vizinhas descreve, assim, tanto a extensão das práticas instrumentais de um sujeito como a socialização das invenções, ou seja, a inovação. Em contrapartida, ela não explica os motivos, que poderemos talvez procurar nas diferentes propostas da teoria da atividade. Ela também não dá conta do processo de invenção, salvo quando sugere que a invenção não se reduz à criação ex nihilo e que o inventor não pode exercer as suas competências desligado do contributo social. 
Gênese instrumental e interações sociais (CERISIER, 2011, p. 114)

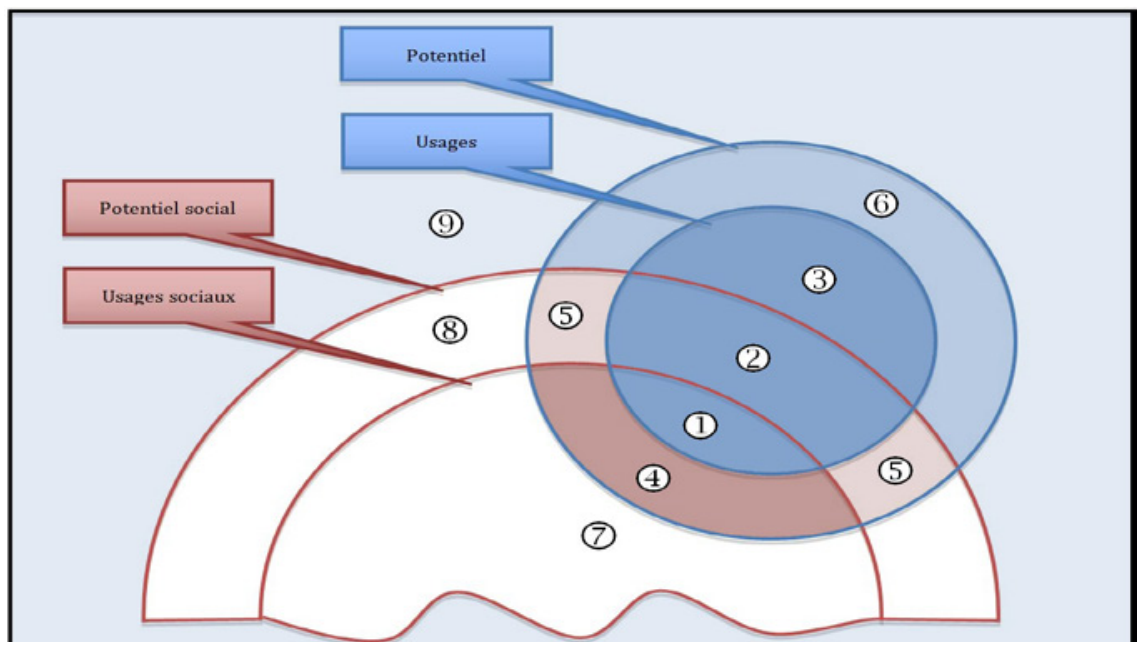

Inspirando-nos nos trabalhos de Robert Lewis (1999) que propôs uma análise das situações de aprendizagem colaborativas retomando o conceito de zona proximal de desenvolvimento, propomos um modelo destinado a dar conta da gênese instrumental.

Cada sujeito dispõe do seu capital de práticas instrumentais (zonas 1, 2 e 3) que define a sua zona proximal de desenvolvimento (zonas 4,5 e 6). De igual modo, o ambiente social (de fato, o conjunto dos grupos sociais aos quais o sujeito pertence) apresenta um capital de práticas instrumentais (zonas 1, 4 e 7) e uma zona proximal de desenvolvimento de novas práticas (zonas 2,5 e 8 ). A escala social como à escala do indivíduo, a zona proximal de desenvolvimento representa um potencial que será atualizado ou não. A inovação consiste na apropriação de uma prática instrumental singular (de uma atividade instrumentada, para usar o vocabulário de Pierre Rabardel) à escala do ambiente social. Dito de outra forma, trata-se de, alternadamente, compreender como uma prática individual vem enriquecer o ambiente social e como outras apropriações individuais podem ter lugar.

Como sugerem os trabalhos de Lewis (ibid.), as zonas nucleares e as zonas proximais de cada pessoa sobrepõem-se parcialmente. Assim, as práticas comprovadas de um indivíduo, quando diferem das 
práticas do ambiente social, poderão potencializar a zona proximal do ambiente social. Inversamente, as práticas partilhadas do ambiente social poderão potencializar as práticas individuais e esta potencialização será tão mais forte quanto a prática seja massiva.

A passagem da zona proximal de desenvolvimento à zona nuclear das práticas instrumentais dependerá da possibilidade da zona nuclear de acolher estes novos usos, que podemos exprimir com uma noção de distância entre usos potenciais e usos reais. Dependerá também da força da potencialização e da sua concordância com as expectativas, os desejos e as necessidades do sujeito. Este processo de potencialização-atualização está próximo da análise que Didier Paquelin propõe para a apropriação (PAQUELIN, 2009) resituando-o numa dinâmica coletiva. Para além de uma representação da dimensão coletiva da gênese instrumental, este modelo fornece argumentos à hipótese da inovação dispositivo no que ela permite situar percursos através dos quais as negociações entre atores permitem a elaboração e a apropriação de novas práticas.

\section{O uso escolar dos tablets táteis à luz da mediação e da gênese instrumental}

A análise de 30 anos de políticas educativas francesas em matéria de tecnologias digitais (1985-2015) mostra ciclos, fundados mais sobre oportunidades tecnoeconômicas que sobre escolhas educativas. As tecnologias derramadas a cada novo ciclo potencializam fortemente a zona proximal de desenvolvimento de indivíduos desejosos de novidade, afim de satisfazerem motivações muitos diversas, e tal tem dado origem a numerosas invenções algumas das quais se tem transformado em inovações. De acordo com o modelo da mediação instrumental, estas invenções são fortemente marcadas pelas características dos artefatos compatíveis com os paradigmas pedagógicos e didáticos no seio dos quais essas invenções os inscrevem.

Assim se seguiram a vaga dos primeiros computadores individuais (Plano IPT em 1985) e o ensino assistido por computador de inspiração comportamentalista, a vaga dos computadores concebidos para usos profissionais da burocrática década de 1990, que suscitou muitas atividades de aprendizagem relevando do paradigma construtivista, depois a conexão progressiva de todos os equipamen- 
tos à Internet (década de 2000) com os maravilhamentos, por vezes abusivos, do socioconstrutivismo. Um olhar retrospetivo confirma o quanto as escolhas pedagógicas foram subordinadas às escolhas tecnológicas, elas mesmas determinadas pelo oportunismo econômico. Hoje, o equipamento que cristaliza os desafios tecnológicos, políticos e econômicos é o tablet tátil e numerosos projetos já levaram à distribuição de milhares de tablets, na hora em que o chefe de Estado anuncia uma dotação generalizada para os alunos do $5^{\circ}$ ano em 2016 (havia 870000 alunos de $5^{\circ}$ ano em 2014).

Este artefato apresenta características singulares. É eficiente do ponto de vista funcional, nómada, conetável e pessoal e não mais unicamente individual. O laboratório TECHNE (EA 6316) está implicado em vários programas de investigação que se debruçam sobre os usos de tablets táteis em contexto escolar. Os resultados destes estudos ainda não foram publicados, mas já é possível elaborar uma síntese sob o ângulo da inovação, à luz do modelo que propomos de zona proximal de desenvolvimento das práticas instrumentais. Como para as outras vagas de equipamento, a inovação esperada (ainda) não aconteceu. Observa-se essencialmente uma recondução de práticas pedagógicas anteriores, instrumentando-as com os novos equipamentos. Como já observava Geneviève Jacquinot em Image et pédagogie (2012) e depois em On demande toujours des inventeurs (1981), a escolarização de artefactos inicialmente produzidos para outros contextos de utilização dificilmente leva em conta as suas especificidades, quer dizer, as modalidades próprias da mediação instrumental que induzem.

Encontramos aqui e ali invenções pedagógicas que repousam sobre a conjunção favorável da participação de professores empreendedores. Todas estas invenções não o são verdadeiramente e reinventase muitas vezes. Nem todas são fatores de progresso, mas faltam-nos avaliações rigorosas para o julgar. Algumas delas são úteis, todavia, não se impõem necessariamente, ficam invisíveis e depois desaparecem. Globalmente, o paradigma da inovação ascendente reivindicado na maior parte destes projetos falha. Isto se deve a uma demasiada fraca estruturação da colaboração entre atores, o que diminui a força da potencialização da zona proximal de desenvolvimento das práticas instrumentais de cada um.

Tal explica-se igualmente por uma demasiado fraca regulação 
dos projetos, que permitiria distinguir aquilo que deveria ser partilhado daquilo que seria preferível ignorar ou abandonar. Por fim, observam-se fortes condicionamentos institucionais reais ou imaginados que freiam as tomadas de iniciativa individuais e limitam a possibilidade de atualizar práticas potenciais.

\section{A invenção arriscando a geometria euclidiana}

É, portanto, a uma política de inovação exigente que convida esta discussão teórica que se inscreve no sulco infatigavelmente talhado por Geneviève Jacquinot-Delaunay, no seio de uma comunidade científica muito ativa há meio século. Numa obra muito recente (2014, p. 89), recorre a uma pirueta para introduzir o capítulo que consagra aos objetos e questões de investigação partilhados com Daniel Peraya. Evoca os seus "caminhos paralelos que, contrariamente ao axioma euclidiano, se bem que paralelos, sempre se cruzaram". O que poderia parecer unicamente artifício literário é, também, uma chave de leitura sobre que é a invenção. Inventar supõe mudar os nossos paradigmas de referência.

\section{REFERÊNCIAS}

AUDRAN, J.; CERISIER, J.-F et al.; CHOLIN, H. Quelle recherche sur et pour l'innovation pédagogique. In: Distance et savoirs, 2007.

DOI: Acessado em 15 outubro 10.3166/ds.5.483-505

CERISIER, J.-F. La désintermédiation comme agent de transformation culturelle dans l'éducation. PELTIER C. (org.) In: La Médiatisation de la formation et de l'apprentissage, Bruxelles, Belgique, De Boeck Université, 2014.

CERISIER, J.-F. Acculturation numérique et médiation instrumentale. Le cas des adolescents français, Poitiers, Université de Poitiers, 2011. Acessado em 14 outubro 2016: http://tel.archives-ouvertes.fr/tel-00922778

DEBLOK, C., Présentation du dossier : Innovation et développement chez Schumpeter. Interventions économiques, 2012. Acessado em 15 outubro 2016. http://interventionseconomiques.revues.org/1852

CHOPLIN, H. Les trois figures de la recherche sur l'enseignement à distance : mouvement, relation, substance. In: Distances et savoirs, 2009. Acessado em 15 
outubro 2016: 10.3166/ds.7.553-570

CROS, F. L'innovation en éducation et en formation. In: Revue française de pédagogie, 1997.

CROS, F. Trois fonctions sociales de l'innovation en éducation et en formation: le cas de la France. BONAMI, M.; GARANT, M. (org.). In: Systèmes scolaires et pilotage de l'innovation. Émergences et implantation du changement, Bruxelles, De Boeck Université, 1996.

HUTCHINS, E. Cognition in the Wild. MIT Press. 1995.

JACQUINOT-DELAUNAY, G. Image et pédagogie. Paris Éditions des Archives contemporaines, Paris: PUF, 2012.

JACQUINOT-DELAUNAY, G; FICHEZ, E. (org.). L'Université et les TIC. Chronique d'une innovation annoncée, Bruxelles, De Boeck Supérieur, 2008.

JACQUINOT-DELAUNAY, G.; CHOPLIN, H. La démarche dispositive au risque de l'innovation, In: Éducation permanente, 2002.

JACQUINOT-DELAUNAY, G. Les sciences de l'éducation et les sciences de la communication en dialogue : à propos des médias et des technologies éducatives. L'Année sociologique, 2001. Acessado em 15 outubro 2016: 10.3917/ anso.012.0392

JACQUINOT-DELAUNAY, G.; MONNOYER, L. (org.). Le Dispositif. Entre usage et concept. Paris, Hermès, CNRS, 1999.

JACQUINOT-DELAUNAY, G. La télévision : terminal cognitive. Réseaux, 1995. Acessado em 15 outubro 2016: http://www.persee.fr/web/revues/home/ prescript/article/reso_0751-7971_1995_num_13_74_2779

JACQUINOT-DELAUNAY, G. Quand il n'est plus possible de faire du neuf avec du vieux. Médiascope, 1993.

JACQUINOT-DELAUNAY, G. On demande toujours des inventeurs.

Communications, 1981. Acessado em 15 outubro 2016: http://www.persee.fr/web/ revues/home/prescript/article/comm_0588-8018_1981_num_33_1_149

LEWIS, R. Apprendre conjointement : une analyse, quelques expériences et un cadre de travail. ROUET, J.-F.; PASSADIĖRE, B. de la; (org.). In: Hypermédias et apprentissages. Actes du quatrième colloque. Paris, EPI, LACO, LIP6, INRP, 1999.

MARIET, F. Laissez-les regarder la télé, Paris, Calmann-Lévy, 1989. 
METZ, C. Images et pédagogie. In: Communications, 1970. Acessado em 15 outubro 2016: http://www.persee.fr/web/revues/home/prescript/article/ comm_0588-8018_1970_num_15_1_1220 DOI : 10.3406/comm.1970.1220

PAQUELIN, D. L'Appropriation des dispositifs numériques de formation. In: Du prescrit aux usages, Paris, L'Harmattan,. 2009

PETIT, L. Enjeux scénographiques et industriels de la conception des ressources numériques : le cas de l'Université en ligne. Tese de doutorado, Université Paris 13, 2007. Disponível em: http://www.observatoire-omic.org/fr/ art/82/enjeux-scenographiques-et-industriels-de-la-conception-des-ressourcesnumeriques-le-cas-de-l-universite-en-ligne.html

PERAYA, D.; PELTIER, C. Une année d'immersion dans un dispositif de formation aux technologies: prise de conscience du potentiel éducatif des TICE, intentions d'action et changement de pratique. In: International Journal of Technologies in Higher Éducation, 2012. Disponível em: http://archive-ouverte. unige.ch/unige: 22664

DOI : $10.7202 / 1012906$ ar

PERAYA, D. Des médias éducatifs aux environnements numériques de travail: médiatisation et médiation. LIQUÈTE, V. (org.), Médiations, 2010.

RABARDEL, P. Les Hommes et les technologies : approche cognitive des instruments contemporains, Paris: Armand Colin, 1995.

REY, O.; FEYFANT, A. Vers une éducation plus innovante et creative. In: Dossier d'actualité veille et analyses, 2012. Acessado em: http://ife.ens-lyon.fr/vst/ DA-Veille/70-janvier-2012.pdf

SAPIR, E. Anthropologie. Éditions de Minuit, 1967.

Acessado em : 10.1522/cla.sae.ant2

SCHUMPETER, J. A. Capitalisme, socialisme et démocratie. Paris, Petite Bibliothèque Payot, 1974. http://dx.doi.org/doi:10.1522/cla.scj.cap

TARDY, M. Le Professeur et les images. Paris, Presses universitaires de France, 1966.

VYGOTSKY, L. Pensée et langage, Paris, Éditions sociales, 1985. 